\title{
Sectoral Impacts of Trade Wars
}

\author{
Wan-Jung Cheng and Ping Wang
}

In recent years, we have witnessed rising trade protectionism with broad ranges of tariffs imposed on intermediate products. In this article, we develop an accounting framework to evaluate the sectoral impacts of the current U.S.-China trade war. We find that U.S. final demand and intermediate demand for goods produced by China decline significantly, with the largest losses occurring in the Electronic and ICT (information and communications technology) industry and the Electrical industry. We obtain sizable deadweight losses for the United States, particularly in the Electronic and ICT; Electrical; and Furniture industries. We also find that, with a leakage rate of 20 percent, total losses to U.S. consumers and importers are $\$ 3.3$ billion, about 0.05 percent of gross U.S. output, whereas the full leakage losses are $\$ 10.7$ billion, or 0.16 percent of gross U.S. output, which is twice as much as the annual welfare gains from the North America Free Trade Agreement. (JEL D20, F10, O50)

Federal Reserve Bank of St. Louis Review, forthcoming 2022.

\section{INTRODUCTION}

Not long after the worldwide Great Recession, protectionism began to rise, from the battled renegotiations of the North America Free Trade Agreement (NAFTA), to the recently escalated U.S.-China trade war, to the ongoing Japan-Korea trade war. Rising protectionism concerns some economists, particularly those who view free trade as beneficial to both developed countries (hereafter, the North) and developing countries (hereafter, the South), by advancing world productivity and enhancing global consumer welfare. A particular concern is that recent trade protectionism has included broad ranges of tariffs imposed on intermediate products (for example, in the United States, nearly 90 percent of intermediate imports from China faced increased tariffs in 2018, as computed by Bown, 2019). Such tariffs violate the so-called Diamond and Mirrlees (1971) principle of optimal taxation: Taxing intermediate goods creates much larger economic distortions and is more harmful to economic development.

Wan-Jung Cheng is an assistant research fellow at Academia Sinica. Ping Wang is the Seigle Family Professor at Washington University in St. Louis, a senior fellow at the Federal Reserve Bank of St. Louis, and a research associate at the National Bureau of Economic Research. We are grateful for useful suggestions from Ching-mu Chen, Tain-Jy Chen, Wen-Tai Hsu, Shin-Kun Peng, and Ray Riezman.

() 2021, Federal Reserve Bank of St. Louis. The views expressed in this article are those of the author(s) and do not necessarily reflect the views of the Federal Reserve System, the Board of Governors, or the regional Federal Reserve Banks. Articles may be reprinted, reproduced, published, distributed, displayed, and transmitted in their entirety if copyright notice, author name(s), and full citation are included. Abstracts, synopses, and other derivative works may be made only with prior written permission of the Federal Reserve Bank of St. Louis. 
In this article, we provide an overview of various key findings in the literature on gains from trade and review the literature on trade wars. We then develop an accounting framework to evaluate the sectoral impacts of the current U.S.-China trade war. Using the international input-output linkage between the two countries and isoelastic demands, we compute how much each U.S. sector's demand for goods produced in China declines when the United States raises its import tariffs as it has under the ongoing trade war. The resulting sectoral deadweight losses and full leakage losses are also computed, where the latter considers an extreme case with no tariff revenues redistributed back to consumers or importers. We find that in response to the trade war, U.S. final demand for Chinese goods drops by $\$ 39$ billion and intermediate demand by $\$ 13$ billion. Among others, the Electronic and Information and Communications Technology (ICT) industry and the Electrical industry suffer the largest losses, with their demands lowered by $\$ 23$ billion and $\$ 9.5$ billion, respectively. U.S. aggregate deadweight losses are about $\$ 1.5$ billion, with the Electronic and ICT; Electrical; Metal Products; and Furniture industries suffering the greatest total losses. With a leakage rate of 20 percent, total losses to U.S. consumers and importers are $\$ 3.3$ billion, about 0.05 percent of gross output and two-thirds as much as the annual welfare gains from NAFTA. The full leakage losses are $\$ 10.7$ billion, or 0.16 percent of gross U.S. output, which is twice as much as the annual welfare gains from NAFTA.

\section{BACKGROUND AND LITERATURE REVIEW}

As argued by Kindleberger (1989), the Smoot-Hawley Tariff Act of 1930 passed by the U.S. Congress led to tariff wars and defensive trade blocs, with a peak sector-weighted average tariff of 24.4 percent for the United States, 29.4 percent for France, and 47.7 percent for the United Kingdom. Germany, Italy, Japan, and the Soviet Union had explicit autarkic aims and militaristic motivations behind their defensive trade blocs, and historians have argued that tariff wars might have subsequently triggered WWII. Thus, when the world returned to peace, many major industrialized countries worked hard on international cooperation. As a result, the General Agreement on Tariffs and Trade (GATT) was signed by 23 nations in Geneva on October 30, 1947, and took effect on January $1,1948$.

Since then, there have been several more rounds of negotiations on international cooperation, including the most crucial Kennedy Round (1964-67), Tokyo Round (1973-79), and Uruguay Round (1986-94), each featuring a major tariff cut of over 30 percent. As a result, the average tariff for major GATT participants reduced from about 22 percent in 1947 all the way down to about 5 percent in 1995. Especially, toward the end of the Uruguay Round agreements, the World Trade Organization was signed by 123 nations in Marrakesh on April 14, 1994, and established on January 1, 1995, replacing the previous workhorse, GATT.

By 2000, the average tariffs in North America and the European Union (EU) were 4.0 percent and 4.2 percent, respectively, whereas in Asia the average was 9.0 percent (in China the average was 16 percent). The relatively high average tariff in Asia should not be surprising, because many economies there are less developed and several are centrally planned to lean toward protecting domestic, less-competitive firms. The prevalence of trade protection is particularly high in the Agricultural; Food and Beverage; and Light industries (often exceeding 20 percent, and even 40 percent in the Agricultural industry). 
The over-half-a-century history of international cooperation is supported by a vast literature on gains from trade. For the sake of brevity, we provide an overview of only the more recent literature pioneered by Arkolakis, Costinot, and Rodriguez-Clare (2012, hereafter ACR). For comparison, we only discuss articles that measure gains from trade by contrasting the welfare under current trade costs with the welfare in an autarky world without international trade (that is, infinite trade costs). Based on a general accounting framework consistent with many static trade models, ACR and their followers found modest gains from trade, usually below 2 percent, compared with autarky. Such gains from trade, however, rise significantly in dynamic frameworks, particularly when technologies are allowed to advance over time (for example, Hsieh, Klenow, and Nath, 2019, find they could be as high as 12.2 percent; Perla, Tonetti, and Waugh, 2021, as high as 13.3 percent; and Bloom et al., 2013, as high as 16.3 percent). In short, in dynamic models with technological improvements, one expects sizable gains from trade because the reduction in trade barriers can promote better technology, raise world productivity, and enhance global consumer welfare. The sizable gains from trade justify the long-devoted effort toward international trade agreements and tariff reductions.

The effort toward trade liberalization has unfortunately reversed lately. We have seen Brexit, the battled renegotiations of NAFTA, the recently escalated U.S.-China trade war, the ongoing JapanKorea trade war, and the possible U.S.-EU trade war-each started by an advanced high-income country. More than three decades ago, Kennan and Riezman (1988) showed that when two countries are engaged in a trade war, the more-advanced larger economy can more easily manipulate international prices and "win" over the less-developed smaller economy. If both countries are of comparable size and at similar development stages, both countries lose. The authors illustrate the battle by using an Edgeworth box, where the cigar-shaped area in the middle represents the set of relative country sizes in which both countries lose a trade war. In this pivotal article, trade protection is imposed strictly on final goods. In practice, this is not the case. In view of the current U.S.China trade war, would it still be true that the United States would win, whereas China would lose?

We begin by illustrating the trade war between two economies that are comparable in size. Consider a hypothetical trade war between the United States and the EU, a case where the relative country sizes lie in the cigar-shaped area. Ossa (2014) found that a large increase in tariffs-of over 50 percent-would only result in a 2 percent welfare loss in the United States and a 2.6 percent loss in the EU.

Next, we turn to the relatively thin literature that focuses on the U.S.-China trade war. This ongoing trade war consists of a series of announcements between the two governments over three years, starting from the Trump administration's memorandum on March 22, 2018, that spelled out the intention to impose a 25 percent tariff on over $\$ 50$ billion of imports from China. Bown (2019) provides a comprehensive review of the detailed content of this trade war. Focusing on the major waves of the trade war in 2018, Amiti, Redding, and Weinstein (2019) find almost complete tariff pass-through that raised consumer prices of importables almost one-for-one (see a graphical illustration in their Figure 4). They find that rising consumer prices lowered consumer welfare, which they estimate as having deadweight losses of $\$ 8.2$ billion (in 2018 prices). This welfare loss is comparable to the welfare gains of NAFTA estimated by Caliendo and Parro (2015). Yet, Amiti, Redding, and Weinstein (2019) also estimate an additional cost of $\$ 14$ billion to U.S. importers and consumers as a result of tariff revenues transferred to the government. Moreover, they find that exporters also suffered due to retaliatory tariffs by China, with lost exports estimated at about 
\$28 billion. Summing both imports and exports together, Amiti, Redding, and Weinstein (2019) estimate that about $\$ 183$ billion of trade was redirected. Notably, such reshuffling may induce severe increases in business costs and resource misallocation that have not been counted in the deadweight loss measures mentioned.

Using a general equilibrium model, Fajgelbaum et al. (2020) compute U.S. losses as a result of rising consumer prices as $\$ 51$ billion for importers and consumers and $\$ 7.2$ billion in aggregate real income by the end of 2018 (based on an aggregate equivalent variation measure frequently used by trade theorists). They further identify that the industrial regions of the Midwest and Northeast suffered less (more domestic protection with less retaliation), whereas the rural regions of the Midwest and Mountain West suffered more.

Turning the focus to firms, Amiti, Kong, and Weinstein (2020) conduct an event-study analysis and find the various waves of the U.S.-China trade war over 2018-19 caused the stock prices of U.S. firms that trade with China to drop by 2.6 percentage points and those of other U.S. firms to drop by 3.4 percentage points, a total drop of 6.0 percentage points. Lower returns to U.S. publicly listed firms thus induced a 1.9-percentage-point reduction in those firms' business investments, which hurts future productivity. In an independent work in this Review, Santacreu and Peake (2020) estimate responses across states and find that those states more exposed to trade experienced lower increases or even decreases in output growth and employment growth between 2018 and 2019.

Finally, one may wonder what happened to the retaliating party-China. While there are few systematic studies, we may learn from a more general framework of the North (which includes the United States) and the South (which includes China), developed by Chen et al. (2020). They consider a global supply chain along which the North produces intermediate goods with more advanced technologies and the South with inferior technologies. Thus, trade in intermediate goods that embody different technologies may act as a mechanism to transfer technology from the North to the South. They find that when the South uses higher-end intermediate goods more intensively along the supply chain in response to a tariff war, its loss may be mitigated by rising average productivity.

\section{AN ACCOUNTING FRAMEWORK}

We now establish an accounting framework to assess sectoral impacts of the trade war. Similar to the argument made by ACR, the advantage of adopting an accounting framework is that the results are less sensitive to model specifics. That is, the framework is consistent with a larger set of models. We base our analysis on three fundamental structures:

(i) There is an international input-output linkage between the source country, the destination country, and the rest of the world (ROW), constituting the global value chain.

(ii) Sectoral demands are isoelastic, where both the demand shifters and the price elasticities are sector specific.

(iii) The increase in import tariffs in the United States during the trade war is completely passed through to U.S. domestic prices.

While the first two are standard assumptions in the trade literature, the third is rooted in the empirical findings of Amiti, Redding, and Weinstein (2019) elaborated on below. 
Consider a Leontief framework that features a global (domestic and international) input-output matrix. Denoting $X$ as gross output, $Z$ as intermediate demand, $F$ as total final demand, and $A=\left[a_{i j}\right]$ as the input technology matrix, according to the Leontief framework we have

$$
X=Z i+F=A X+F .
$$

Under this Leontief framework, production of one unit of the $j$ th good uses $a_{i j}$ units of the $i$ th good as inputs. The Leontief input-output framework is based on a Leontief fixed-proportion technology. The input coefficients are allowed to vary over time, but how such coefficients evolve dynamically is not modeled explicitly.

Denote $I$ as the identity matrix and let

$$
\Omega \equiv(I-A)^{-1},
$$

and by rearranging (1) we know that final demand $F$ and global supply $X$ satisfy the following relationship:

$$
X=\Omega \cdot F
$$

$\Omega$ is the Leontief inverse matrix:

$$
\Omega=\left[\omega_{k(i) s(j)}\right],
$$

where $\omega_{k(i) s(j)}$ captures the backward linkage effect of a change in the final demand for goods in sector $j$ sourced from country $s$ on the change in the output of sector $i$ in country $k$.

We first provide a simplified example for illustration and then construct the general framework. Suppose there are three countries, the United States, China, and ROW, denoted as $\{U, C, R\}$, and two sectors, denoted as $\{1,2\}$. To describe the international flow of goods, we denote the source country as country $s$ and the destination country as country $d$. Let $X_{k j}$ denote the gross output of sector $j$ in country $k$ and $F_{s j}^{d}$ country $d$ 's final demand for sector- $j$ goods sourced from country $s$. The Leontief framework thus implies that

$$
\left[\begin{array}{l}
X_{U 1} \\
X_{U 2} \\
X_{C 1} \\
X_{C 2} \\
X_{R 1} \\
X_{R 2}
\end{array}\right]=\Omega \cdot\left[\begin{array}{c}
F_{U 1}^{U}+F_{U 1}^{C}+F_{U 1}^{R} \\
F_{U 2}^{U}+F_{U 2}^{C}+F_{U 2}^{R} \\
F_{C 1}^{U}+F_{C 1}^{C}+F_{C 1}^{R} \\
F_{C 2}^{U}+F_{C 2}^{C}+F_{C 2}^{R} \\
F_{R 1}^{U}+F_{R 1}^{C}+F_{R 1}^{R} \\
F_{R 2}^{U}+F_{R 2}^{C}+F_{R 2}^{R}
\end{array}\right],
$$

where, for example, $F_{C 1}^{U}$ and $F_{C 2}^{U}$ are final U.S. demand for China's goods in sectors 1 and 2, respectively. Moreover, we have 


$$
\left[\begin{array}{l}
\Delta X_{U 1} \\
\Delta X_{U 2} \\
\Delta X_{C 1} \\
\Delta X_{C 2} \\
\Delta X_{R 1} \\
\Delta X_{R 2}
\end{array}\right]=\Omega \cdot\left[\begin{array}{c}
\Delta F_{U 1}^{U}+\Delta F_{U 1}^{C}+\Delta F_{U 1}^{R} \\
\Delta F_{U 2}^{U}+\Delta F_{U 2}^{C}+\Delta F_{U 2}^{R} \\
\Delta F_{C 1}^{U}+\Delta F_{C 1}^{C}+\Delta F_{C 1}^{R} \\
\Delta F_{C 2}^{U}+\Delta F_{C 2}^{C}+\Delta F_{C 2}^{R} \\
\Delta F_{R 1}^{U}+\Delta F_{R 1}^{C}+\Delta F_{R 1}^{R} \\
\Delta F_{R 2}^{U}+\Delta F_{R 2}^{C}+\Delta F_{R 2}^{R}
\end{array}\right] .
$$

Note that $\Omega=\left[\omega_{k(i) s(j)}\right]$ captures the effect of the international input-output linkage. For example, $\omega_{U(i) C(j)}$ captures the effect of a change in the final demand for Chinese goods of sector $j$ (from $\left.\Delta F_{C j}^{U}, \Delta F_{C j}^{C}, \Delta F_{C j}^{R}\right)$ on the change in the output of U.S. sector $i\left(\Delta X_{U i}\right)$.

We further suppose that the rise in the import tariff on Chinese goods imposed by the United States only affects $F_{C j}^{U}$. That is, U.S. final demand (including final consumption and investment) for domestic goods and imports from ROW are not affected, and China's and ROW's final demands for goods from any country are not affected. The latter assumption is natural given that we focus on the tariff increases imposed by the United States and do not consider retaliatory tariffs by China. The former assumption restricts the United States from substituting between Chinese goods and other goods. ${ }^{1}$ Given these assumptions, (3) becomes

$$
\left[\begin{array}{l}
\Delta X_{U 1} \\
\Delta X_{U 2} \\
\Delta X_{C 1} \\
\Delta X_{C 2} \\
\Delta X_{R 1} \\
\Delta X_{R 2}
\end{array}\right]=\left[\omega_{k(i) s(j)}\right] \cdot\left[\begin{array}{c}
0 \\
0 \\
\Delta F_{C 1}^{U} \\
\Delta F_{C 2}^{U} \\
0 \\
0
\end{array}\right] .
$$

To estimate $\Delta F_{C j}^{U}$ we need to specify the sectoral demand structure for imports, and we adopt the isoelastic demand assumption that is commonly used in the trade literature. Let $q_{s j}^{d}$ denote the quantity of sector- $j$ goods imported from country $s$ to country $d$. By properly choosing the base year, let the price $p_{s j}^{d}$ be normalized by $p_{s j}^{d}=1+\tau_{s j}^{d}$, where $\tau_{s j}^{d}$ is country $d^{\prime}$ 's tariff rate imposed on imports in sector $j$ from source country $s$. Given isoelastic demand, U.S. demand for sector $-j$ goods from China in logs before the trade war is given by

$$
\ln q_{s j}^{d}=\ln D_{j}+\sigma_{s j}^{d} \cdot \ln \left(1+\tau_{s j}^{d}\right)
$$

where $\sigma_{s j}^{d}<0$ is the import demand elasticity, which is estimated by subtracting the fixed effects for the destination country from the fixed effects for the source country. The demand scaling parameter $D_{j}$ is thus by definition specified as $D_{j}=q_{s j}^{d} /\left(1+\tau_{s j}^{d}\right)^{\sigma_{s j}^{d}}$.

In the World Input-Output Database (WIOD), $F_{s j}^{d}$ is expressed in terms of value. Thus, writing the demand relationship in terms of values, we have

$$
\ln F_{s j}^{d} \equiv \ln p_{j}+\ln q_{s j}^{d}=\ln p_{j}+\ln D_{j}+\sigma_{s j}^{d} \cdot \ln \left(1+\tau_{s j}^{d}\right)=\ln V_{j}+\sigma_{s j}^{d} \cdot \ln \left(1+\tau_{s j}^{d}\right),
$$


where $V_{j} \equiv p_{j} D_{j}$. Let the prime symbol (') indicate the quantity or price after the trade war. Analogously, the value of demand after the trade war is

$$
\ln F_{s j}^{d^{\prime}} \equiv \ln p_{j}^{\prime}+q_{s j}^{d^{\prime}}=\ln V_{j}^{\prime}+\sigma_{s j}^{d} \cdot \ln \left(1+\tau_{s j}^{d^{\prime}}\right),
$$

where

$$
V_{j}^{\prime} \equiv p_{j}^{\prime} D_{j}=\frac{p_{j}^{\prime} q_{s j}^{d}}{\left(1+\tau_{s j}^{d}\right)^{\sigma_{s j}^{d}}}=\frac{p_{j}{ }^{\prime}}{p_{j}} \cdot \frac{F_{s j}^{d}}{\left(1+\tau_{s j}^{d}\right)^{\sigma_{s j}^{d}}}=\frac{p_{j}{ }^{\prime}}{p_{j}} \cdot V_{j},
$$

where the last equality is calculated by applying (5). Empirical evidence in Amiti, Redding, and Weinstein (2019), based on monthly data from January 2017 to December 2018, suggests that "the Trump administration's tariff changes have been almost entirely passed through into domestic prices" (p. 197). Their findings are consistent with more recent studies by Fajgelbaum et al. (2020) and Cavallo et al. (2021). Thus, based on all of these findings, we assume complete pass-through of tariffs in our analysis. ${ }^{2}$ That is, we have

$$
\frac{p_{j}^{\prime}}{p_{j}}=\frac{1+\tau_{s j}^{d^{\prime}}}{1+\tau_{s j}^{d}} .
$$

Taking the difference between (5) and (6) and applying (7) and (8), we obtain

$$
\ln \left(\frac{F_{s j}^{d^{\prime}}}{F_{s j}^{d}}\right)=\left(1+\sigma_{s j}^{d}\right) \cdot \ln \left(\frac{1+\tau_{s j}^{d^{\prime}}}{1+\tau_{s j}^{d}}\right),
$$

or, equivalently,

$$
1+\frac{\Delta F_{s j}^{d}}{F_{s j}^{d}}=\left(1+\frac{\Delta \tau_{s j}^{d}}{1+\tau_{s j}^{d}}\right)^{1+\sigma_{s j}^{d}} .
$$

Accordingly, the impact of the trade war on country $d$ 's final demand for country s's goods in sector $j$ in response to country $d$ 's tariff hike is measured by

$$
\Delta F_{s j}^{d}=\left[\left(1+\frac{\Delta \tau_{s j}^{d}}{1+\tau_{s j}^{d}}\right)^{1+\sigma_{s j}^{d}}-1\right] \cdot F_{s j}^{d} .
$$

Let $\tau$ denote the average tariff in destination country $d$, and consider a trade war that causes the average tariff to increase by $\Delta \tau$. The different tariff rates in different sectors are reflected by country $d$ 's tariff coverage rate imposed on imports in sector $j$ from source country $s$, which is denoted by $T C R_{s j}^{d}$ and can be computed from the data. ${ }^{3}$ The sector-specific tariff increase is thus measured by $\Delta \tau_{s j}^{d} /\left(1+\tau_{s j}^{d}\right)=\left(T C R_{s j}^{d} \cdot \Delta \tau\right) /(1+\tau)$. The import demand elasticity $\sigma_{s j}^{d}$ can be measured by the trade elasticity, which captures the impact of trade costs such as tariffs on the quantity of country $d$ 's demand for sector- $j$ goods. From (4), the impact on sectoral output can be computed as 


$$
\left(\begin{array}{l}
\Delta X_{U 1} \\
\Delta X_{U 2} \\
\Delta X_{C 1} \\
\Delta X_{C 2} \\
\Delta X_{R 1} \\
\Delta X_{R 2}
\end{array}\right)=\left[\begin{array}{l}
\sum_{j=1,2} \omega_{U(1) C(j)} \cdot \Delta F_{C j}^{U} \\
\sum_{j=1,2} \omega_{U(2) C(j)} \cdot \Delta F_{C j}^{U} \\
\sum_{j=1,2} \omega_{C(1) C(j)} \cdot \Delta F_{C j}^{U} \\
\sum_{j=1,2} \omega_{C(2) C(j)} \cdot \Delta F_{C j}^{U} \\
\sum_{j=1,2} \omega_{R(1) C(j)} \cdot \Delta F_{C j}^{U} \\
\sum_{j=1,2} \omega_{R(2) C(j)} \cdot \Delta F_{C j}^{U}
\end{array}\right] .
$$

$\Delta X_{k j}$ derived by (11) measures how much the output of sector $j$ in country $k$ would be affected through the international input-output linkage when the United States raises its import tariff on Chinese goods by $\Delta \tau$ on average.

Some comments are in order. As mentioned above, this impact measure is based on a general accounting framework that is consistent with a wide class of models. Because trade elasticities could be measured in the short or the long run, the potential dynamic effects could be partially accounted for. The only limitation is that in (3), we assumed that, in response to the trade war, (i) U.S. final demand for its own and ROW's goods in any sector $\left(\Delta F_{U j}^{U}\right.$ and $\left.\Delta F_{R j}^{U}\right)$ remain unchanged and (ii) China's and ROW's final demands for any country's goods in any sector remain unchanged. While the latter is not our concern, because we are not characterizing U.S. exporter responses, the former prohibits us from estimating redirection of U.S. demand to other sources. Think of this scenario as being under the framework of Alvarez and Lucas (2007), with buyers searching globally for the cheapest goods of similar quality. Imports from China are associated with a vector of observed minimum prices, but what would the next-highest augmented trade price be? We cannot know unless we have empirically observed what happens after the trade war when redirection starts. The reshuffling of the global value chain requires deep structures of international demand and pricing strategies, which is beyond the scope of this article.

Now we are ready to extend to the general framework. Suppose there are $K$ countries and $J$ sectors. The U.S. tariff increase imposed on Chinese imports by $\Delta \tau$ on average would impact the output in country $k$ 's sector $i$ through the international input-output linkage as follows:

$$
\left[\Delta X_{k i}\right]_{k \in K, i \in J}=\left[\sum_{j=1}^{J} \omega_{k(i) C(j)} \cdot\left(\left(1+\frac{\Delta \tau_{s j}^{d}}{1+\tau_{s j}^{d}}\right)^{1+\sigma_{s j}^{d}}-1\right) \cdot F_{C j}^{U}\right]_{k \in K, i \in J} .
$$

Note that this impact measure is the general form of (11).

To compute welfare losses, we extend the framework in Amiti, Redding, and Weinstein (2019). They note that almost complete pass-through of tariffs means that the source country's supply of exports is close to perfectly elastic, which is illustrated in Figure 2 in their article. Following their analysis, we compute the sector-specific deadweight losses in destination country $d$ under a trade war it initiates toward source country $s$ as follows:

$$
D W L_{s j}^{d}=\frac{1}{2} \cdot \Delta \tau_{s j}^{d} \cdot\left|\Delta q_{s j}^{d}\right|,
$$


where $q_{s j}^{d}$ is the quantity of sector- $j$ goods imported from country $s$ to country $d$, and the unobservable quantity changes $\Delta q_{s j}^{d}$ will be estimated. Recall that from isoelastic demand,

$$
q_{s j}^{d}=D_{j} \cdot\left(p_{s j}^{d}\right)^{\sigma_{s j}^{d}}
$$

we have inverse demand $p_{s j}^{d}=\left(\frac{q_{s j}^{d}}{D_{j}}\right)^{\frac{1}{\sigma_{s j}^{d}}}$, and hence in value terms,

$$
v_{s j}^{d} \equiv p_{s j}^{d} \cdot q_{s j}^{d}=\left(D_{j}\right)^{-\frac{1}{\sigma_{s j}^{d}}} \cdot\left(q_{s j}^{d}\right)^{1+\frac{1}{\sigma_{s j}^{d}}} .
$$

After the trade war, we have $q_{s j}^{d^{\prime}}=D_{j} \cdot\left(p_{s j}^{d^{\prime}}\right)^{\sigma_{s j}^{d}}$. Thus,

$$
v_{s j}^{d^{\prime}}=\left(D_{j}\right)^{-\frac{1}{\sigma_{s j}^{d}}} \cdot\left(q_{s j}^{d^{\prime}}\right)^{1+\frac{1}{\sigma_{s j}^{d}}}=v_{s j}^{d} \cdot\left(\frac{q_{s j}^{d^{\prime}}}{q_{s j}^{d}}\right)^{1+\frac{1}{\sigma_{s j}^{d}}}
$$

and

$$
\Delta v_{s j}^{d} \equiv v_{s j}^{d^{\prime}}-v_{s j}^{d}=v_{s j}^{d} \cdot\left[\left(1+\frac{\Delta q_{s j}^{d}}{q_{s j}^{d}}\right)^{1+\frac{1}{\sigma_{s j}^{d}}}-1\right] .
$$

Therefore, from (14) and with the price prior to the trade war normalized by $p_{s j}^{d}=1+\tau_{s j}^{d}$, we can rewrite the quantity changes as follows:

$$
\Delta q_{j}=-\left[1-\left(1+\frac{\Delta v_{s j}^{d}}{v_{s j}^{d}}\right)^{\frac{\sigma_{s j}^{d}}{1+\sigma_{s j}^{d}}}\right] \cdot q_{j}=-\left[1-\left(1+\frac{\Delta v_{s j}^{d}}{v_{s j}^{d}}\right)^{\frac{\sigma_{s j}^{d}}{1+\sigma_{s j}^{d}}}\right] \cdot \frac{v_{s j}^{d}}{1+\tau_{s j}^{d}},
$$

where $v_{s j}^{d}$ is the value of sector- $j$ goods imported from country $s$ to country $d$. Denote $Z_{s j}^{d}$ as country $d$ 's intermediate demand for sector- $j$ goods from country $s$. The total value of sector- $j$ goods imported from country $s$ to country $d$ is the sum of intermediate and final demand, whereby $\Delta Z_{s j}^{d}$ can be computed by

$$
\Delta Z_{s j}^{d}=\left[\left(1+\frac{\Delta \tau_{s j}^{d}}{1+\tau_{s j}^{d}}\right)^{1+\sigma_{s j}^{d}}-1\right] \cdot Z_{s j}^{d}
$$

Thus, the deadweight losses defined in (13) become

$$
\left.D W L_{s j}^{d}=\frac{1}{2} \cdot \Delta \tau_{s j}^{d} \cdot \llbracket 1-\left(1+\frac{\Delta v_{s j}^{d}}{v_{s j}^{d}}\right)^{\frac{\sigma_{s j}^{d}}{1+\sigma_{s j}^{d}}}\right] \cdot \frac{v_{s j}^{d}}{1+\tau_{s j}^{d}} \mid
$$


with $v_{s j}^{d}=F_{s j}^{d}+Z_{s j}^{d}$ and $\Delta v_{s j}^{d}=\Delta F_{s j}^{d}+\Delta Z_{s j}^{d}$. Note that the implicit assumptions in Amiti, Redding, and Weinstein (2019) include a partial equilibrium, perfect competition, U.S. tariff increases treated as an exogenous shock, and no retaliation by China. The increase in tariff revenue due to the trade war is computed as

$$
\begin{aligned}
\operatorname{TRev}_{s j}^{d} & =\Delta \tau_{s j}^{d} \cdot q_{s j}^{d^{\prime}}=\Delta \tau_{s j}^{d} \cdot\left(1+\frac{\Delta q_{s j}^{d}}{q_{s j}^{d}}\right) \cdot q_{s j}^{d} \\
& =\Delta \tau_{s j}^{d} \cdot\left(1+\frac{\Delta v_{s j}^{d}}{v_{s j}^{d}}\right)^{\frac{\sigma_{s j}^{d}}{1+\sigma_{s j}^{d}}} \cdot \frac{v_{s j}^{d}}{1+\tau_{s j}^{d}},
\end{aligned}
$$

where the last equality is calculated by applying (14) and $p_{s j}^{d}=1+\tau_{s j}^{d}$.

As mentioned by Amiti, Redding, and Weinstein (2019), the cost of the U.S. tariff increase is twofold. First, the higher prices caused by the trade war lead to distortion of domestic consumption and production decisions, constituting the deadweight losses captured by (13). The increase in tariffs widens the wedge between the prices charged by foreign producers and the prices paid by domestic consumers and producers and leads to further distortion of final demand and intermediate demand. Second, complete tariff pass-through suggests that higher prices resulting from increased tariffs were almost entirely borne by U.S. consumers and importers. Incremental tariff revenue is thus a transfer from domestic consumers to the government. If the government does not use the tariff revenue to generate social welfare, then the welfare loss from the tariff war to the economy equals the sum of deadweight losses (13) and the incremental tariff payments (17).

Formally, we define a leakage rate $\lambda$ as the fraction of tariff revenues not redistributed back to consumers or importers but used for other purposes that do not benefit consumers or importers. In our quantitative analysis below, we will link $1-\lambda$ with the fiscal multiplier. Total losses are thus given by

$$
T L o s s_{s j}^{d}=D W L_{s j}^{d}+\lambda \cdot T R e v_{s j}^{d} .
$$

Thus, deadweight losses, $D W L$, are a special case with $\lambda=0$ and full leakage losses, FLoss, are a special case with $\lambda=1$. Total losses, TLoss, are in between the lower-bound measure of $D W L$ and the upper-bound measure of FLoss.

\section{QUANTITATIVE ANALYSIS}

We are now prepared to compute the impact measures for the ongoing U.S.-China trade war, where the destination country $d$ is the United States and the source country $s$ is China.

The primary data source is the World Input-Output Tables (WIOT) from the 2016 release of the WIOD (see the discussion in Timmer et al., 2015, concerning the 2013 release). We then adopt the trade elasticities from Caliendo and Parro (2015), using the estimates with 1 percent trimming, and obtain the U.S. tariff coverage rates by sector and the average tariff increase of $\Delta \tau=9.3$ percent from Bown (2019). ${ }^{4}$ Because sectoral classifications in these three sources are based on different systems, we make additional adjustments. The final list of sectors (industries) is provided in Table 1, and the sectoral trade elasticities and tariff coverage rates are provided in Table 2. 


\section{Table 1}

\section{Classifications of Sectors}

\begin{tabular}{|c|c|c|c|}
\hline Sectors & WIOD sectors & Caliendo-Parro (2015) sectors & Bown-Crowley (2016) sectors \\
\hline Primary & A01-03 & Agriculture & $\begin{array}{c}\text { Hides and Skins; Animal Products; } \\
\text { Vegetable Products }\end{array}$ \\
\hline Food and Tobacco & C $10-12$ & Food & Prepared Food \\
\hline Textile & C13-15 & Textile & Textiles and Clothing; Footwear \\
\hline Wood & C16 & Wood & Wood \\
\hline Paper & $\mathrm{C} 17$ & Paper & Wood \\
\hline Printing and Media & C18 & Paper & Wood \\
\hline Petroleum & C19 & Petroleum & Fuel \\
\hline Chemicals & $\mathrm{C} 20$ & Chemicals & Chemicals \\
\hline Pharmaceutical & C21 & Chemicals & Chemicals \\
\hline Plastic and Rubber & $\mathrm{C} 22$ & Plastic & Plastics and Rubber \\
\hline Non-metallic Mineral & $\mathrm{C} 23$ & Minerals & Mineral Products; Stone and Glass \\
\hline Basic Metals & $\mathrm{C} 24$ & Basic Metals & Metals \\
\hline Metal Products & $\mathrm{C} 25$ & Metal Products & Metals \\
\hline Electronic and ICT & C26 & Communication; Office; Medical & $\begin{array}{l}\text { Electronics and } \\
\text { Electrical Machinery }\end{array}$ \\
\hline Electrical Equipment & $\mathrm{C} 27$ & Electrical & $\begin{array}{l}\text { Electronics and } \\
\text { Electrical Machinery }\end{array}$ \\
\hline Machinery & $\mathrm{C} 28$ & Machinery & Machinery \\
\hline Motor Vehicles & C29 & Auto (Motor Vehicles) & Transportation Equipment \\
\hline Other Transport & C30 & Other Transport & Transportation Equipment \\
\hline Furniture & $C 31-32$ & Other & Miscellaneous \\
\hline Repair and Installation & C33 & Machinery & Machinery \\
\hline
\end{tabular}

In the analysis below, we use primarily the classification of the 2016 WIOD release, which classifies sectors according to International Standard Industrial Classification Revision 4. Specifically, it separates the Furniture industry from the Other Wood Products industry; the Printing industry from the Paper industry; the Pharmaceutical industry from the Chemical industry; the Machinery Repair and Installation industry from the Machinery industry; and the Motor Vehicles industry from the Other Transport industry. Whenever a measure for a sub-industry industry is not available, we apply the measure for the broader industry to all sub-industries.

Two points are noteworthy. First, in the Wood; Paper; Petroleum; and Electrical industries, trade elasticities are high and hence U.S. demand for products from these industries is more sensitive to a tariff war. Second, in more than half of the industries under study, tariff coverage rates exceed 50 percent. In the Food and Tobacco; Transport (Motor Vehicles and Other Transport); Metal 
Table 2

Sectoral Trade Elasticities and Tariff Coverage Rates

\begin{tabular}{lcc} 
Sector & Trade elasticity & Tariff coverage rate (\%) \\
\hline Primary & -9.11 & $77.99^{\dagger}$ \\
\hline Food and Tobacco & -2.62 & 94.22 \\
\hline Textile & -8.1 & $9.84^{\ddagger}$ \\
\hline Wood & -11.5 & 69.92 \\
\hline Paper & -16.52 & 69.92 \\
\hline Printing and Media & -16.52 & 69.92 \\
\hline Petroleum & -64.85 & 84.63 \\
\hline Chemicals & -3.13 & 55.76 \\
\hline Pharmaceutical & -3.13 & 55.76 \\
\hline Plastic and Rubber & -1.67 & 70.42 \\
\hline Non-metallic Mineral & -2.41 & $47.65^{\S}$ \\
\hline Basic Metals & -3.28 & 85.56 \\
\hline Metal Products & -6.99 & 85.56 \\
\hline Electronic and ICT & $-8.54^{*}$ & 45.11 \\
\hline Electrical Equipment & -12.91 & 45.11 \\
\hline Machinery & -1.45 & 51.49 \\
\hline Motor Vehicles & -1.84 & 91.86 \\
\hline Other Transport & -0.39 & 91.86 \\
\hline Furniture & -3.98 & 66.26 \\
\hline Repair and Installation & -1.45 & 51.49
\end{tabular}

NOTE: *Average of $-3.95,-12.95$, and $-8.71 .{ }^{\dagger}$ Average of $100,78.88$, and 55.10 . $\neq$ Average of 12.66 and $7.01 .{ }^{\S}$ Average of 44.11 and 51.19. See Table 1 for the corresponding sectors for the averages.

(Basic Metal and Metal Products); and Petroleum industries, tariff coverage rates are especially high-above 80 percent each. Thus, U.S. demand for products from these industries is more likely to be discouraged.

We use WIOT data and make the base year 2014, the last year for which data are available. We first compute U.S. final demand for sector- $j$ goods from China as a ratio of total U.S. final demand in sector $j$, defined as

$$
F D R_{C j}^{U}=\frac{F_{C j}^{U}}{\sum_{k=1}^{K} F_{k j}^{U}} .
$$

Similarly, we also compute U.S. intermediate demand for sector- $j$ goods from China as a ratio of total U.S. intermediate demand in sector $j$, defined as

$$
I D R_{C j}^{U}=\frac{Z_{C j}^{U}}{\sum_{k=1}^{K} Z_{k j}^{U}} .
$$




\section{Table 3}

\section{China's Contribution to U.S. Demand}

\begin{tabular}{|c|c|c|c|}
\hline WIOD sector & $F D R_{C j}^{U}(\%)$ & $I D R_{C j}^{U}(\%)$ & $D R_{C j}^{U}(\%)$ \\
\hline A01-03: Primary & 0.4 & 0.1 & 0.2 \\
\hline C10-12: Food and Tobacco & 0.8 & 0.2 & 0.6 \\
\hline C13-15: Textile & 29.5 & 4.9 & 25.0 \\
\hline C16: Wood & 7.2 & 1.9 & 3.1 \\
\hline C17: Paper & 2.4 & 1.4 & 1.6 \\
\hline C18: Printing and Media & 0.9 & 0.4 & 0.8 \\
\hline C19: Petroleum & 0.2 & 0.6 & 0.3 \\
\hline C20: Chemicals & 1.1 & 3.8 & 2.6 \\
\hline C21: Pharmaceutical & 2.1 & 0.8 & 1.4 \\
\hline C22: Plastic and Rubber & 8.4 & 2.7 & 4.5 \\
\hline C23: Non-metallic Mineral & 9.8 & 3.4 & 5.2 \\
\hline C24: Basic Metals & 26.0 & 1.1 & 2.0 \\
\hline C25: Metal Products & 10.9 & 2.4 & 4.2 \\
\hline C26: Electronic and ICT & 26.1 & 13.6 & 22.4 \\
\hline C27: Electrical Equipment & 26.0 & 11.7 & 20.4 \\
\hline C28: Machinery & 6.7 & 7.3 & 6.9 \\
\hline C29: Motor Vehicles & 0.9 & 3.6 & 1.6 \\
\hline C30: Other Transport & 1.5 & 1.1 & 1.4 \\
\hline C31-32: Furniture & 11.6 & 2.6 & 10.4 \\
\hline C33: Repair and Installation & 0.0 & 0.0 & 0.0 \\
\hline Total & 7.1 & 2.7 & 5.1 \\
\hline
\end{tabular}

Finally, we define the aggregate demand ratio of U.S. imports from China as follows:

$$
D R_{C j}^{U}=\frac{F_{C j}^{U}+Z_{C j}^{U}}{\sum_{k=1}^{K}\left(F_{k j}^{U}+Z_{k j}^{U}\right)},
$$

which captures overall U.S. dependence on Chinese imports. We report FDR, IDR, and $D R$ in Table 3 .

The results suggest that in the Textile; Electronic and ICT, Electrical Equipment; Basic Metals; Furniture; and Metal Product industries, U.S. final demand is highly China dependent, with each industry's demand ratio exceeding 10 percent. U.S. intermediate demand is highly China dependent only for the Electronic and ICT industry and Electrical Equipment industry, which is not surprising, because Chinese products for these industries are more heavily downstream in the global value chain. By aggregation, overall U.S. dependence on Chinese imports is particularly high in the Textile; Electronic and ICT; Electrical Equipment; and Furniture industries.

Using the formula derived in Section 3, we can compute the measures of sectoral impact on output, $\left\{\Delta X_{k j}\right\}_{k=\{U, C, R\}}$; deadweight losses, $D W L_{C j}^{U}$; and tariff revenues, $T R e v_{C j}^{U}$, as follows. There are 
three countries (the United States, China, and ROW) and 21 WIOD sectors (as listed in Table 1), including a "Remainder" sector (not shown) consisting of all non-agriculture and non-manufacturing industries. Following Bown (2019), we set $\tau=3.1$ percent and $\tau^{\prime}=12.4$ percent. In the WIOT, the data are observed as $X=Z i+F$, where $X, Z$, and $F$ are gross output, intermediate demand, and final demand, respectively. ${ }^{5}$ Specifically, the intermediate demand matrix is expressed as

$$
Z=\left[\begin{array}{ccccccccc}
Z_{U(1) U(1)} & \cdots & Z_{U(1) U(21)} & Z_{U(1) C(1)} & \cdots & Z_{U(1) C(21)} & Z_{U(1) R(1)} & \cdots & Z_{U(1) R(21)} \\
\vdots & \ddots & \vdots & \vdots & \ddots & \vdots & \vdots & \ddots & \vdots \\
Z_{U(21) U(1)} & \cdots & Z_{U(21) U(21)} & Z_{U(21) C(1)} & \cdots & Z_{U(21) C(21)} & Z_{U(21) R(1)} & \cdots & Z_{U(21) R(21)} \\
Z_{C(1) U(1)} & \cdots & Z_{C(1) U(21)} & Z_{C(1) C(1)} & \cdots & Z_{C(1) C(21)} & Z_{C(1) R(1)} & \cdots & Z_{C(1) R(21)} \\
\vdots & \ddots & \vdots & \vdots & \ddots & \vdots & \vdots & \ddots & \vdots \\
Z_{C(21) U(1)} & \cdots & Z_{C(21) U(21)} & Z_{C(21) C(1)} & \cdots & Z_{C(21) C(21)} & Z_{C(21) R(1)} & \cdots & Z_{C(21) R(21)} \\
Z_{R(1) U(1)} & \cdots & Z_{R(1) U(21)} & Z_{R(1) C(1)} & \cdots & Z_{R(1) C(21)} & Z_{R(1) R(1)} & \cdots & Z_{R(1) R(21)} \\
\vdots & \ddots & \vdots & \vdots & \ddots & \vdots & \vdots & \ddots & \vdots \\
Z_{R(21) U(1)} & \cdots & Z_{R(21) U(21)} & Z_{R(21) C(1)} & \cdots & Z_{R(21) C(21)} & Z_{R(21) R(1)} & \cdots & Z_{R(21) R(21)}
\end{array}\right],
$$

where $z_{k(i) s(j)}$ denotes the demand for country $k$ 's sector- $i$ goods from sector $j$ in country $s$. The Leontief input technology matrix can be thus calculated as $A=\left[a_{k(i) s(j)}\right]=\left[\frac{z_{k(i) s(j)}}{X_{s(j)}}\right]$, and therefore we know that $X=A X+F=\Omega F$, where $\Omega=\left[\omega_{k(i) s(j)}\right]$. Given this matrix and the tariff coverage rates, the explicit form of the sectoral impact on output through the international input-output linkage (12) can be expressed as

$$
\Delta X_{k i}=\sum_{j=1}^{20} \omega_{k(i) C(j)} \cdot \Delta F_{C j}^{U} \text { for } k \in\{U, C, R\}, i=1 \ldots 20,
$$

where

$$
\Delta F_{C j}^{U}=\left[\left(1+\frac{T C R_{C j}^{U} \cdot \Delta \tau}{1+\tau}\right)^{1+\sigma_{C j}^{U}}-1\right] \cdot F_{C j}^{U}
$$

The explicit form of the deadweight losses (13) for the United States is thus given by

$$
D W L_{C j}^{U}=\frac{1}{2} \cdot T C R_{C j}^{U} \cdot \Delta \tau \cdot\left|\Delta q_{C j}^{U}\right| \text { for } j=1 \ldots 20,
$$

wherein we are particularly interested in three measures:

- Measure 1 (our benchmark, as in Amiti, Redding, and Weinstein, 2019), considers both final demand and intermediate demand:

$$
\Delta q_{C j}^{U}=-\left[1-\left(1+\frac{\Delta F_{C j}^{U}+\Delta Z_{C j}^{U}}{F_{C j}^{U}+Z_{C j}^{U}}\right)^{\frac{\sigma_{C j}^{U}}{1+\sigma_{C j}^{U}}}\right] \cdot \frac{F_{C j}^{U}+Z_{C j}^{U}}{1+\tau},
$$


where U.S. intermediate demand for sector-j goods from China $Z_{C j}^{U}$ is calculated as

$$
Z_{C j}^{U}=\sum_{i=1}^{21} z_{C(j) U(i)}
$$

and

$$
\Delta Z_{C j}^{U}=\left[\left(1+\frac{T C R_{C j}^{U} \cdot \Delta \tau}{1+\tau}\right)^{1+\sigma_{C j}^{U}}-1\right] \cdot Z_{C j}^{U}
$$

- Measure 2 considers only final demand:

$$
\Delta q_{C j}^{U}=-\left[1-\left(1+\frac{\Delta F_{C j}^{U}}{F_{C j}^{U}}\right)^{\frac{\sigma_{C j}^{U}}{1+\sigma_{C j}^{U}}}\right] \cdot \frac{F_{C j}^{U}}{1+\tau} .
$$

- Measure 3 considers only private consumption demand:

$$
\Delta q_{C j}^{U}=-\left[1-\left(1+\frac{\Delta \operatorname{conns}_{C j}^{U}}{F \operatorname{cons}_{C j}^{U}}\right)^{\frac{\sigma_{C j}^{U}}{1+\sigma_{C j}^{U}}}\right] \cdot \frac{F \operatorname{cons}_{C j}^{U}}{1+\tau},
$$

where note that in the WIOT the variables CONS_h $h$ and CONS_np denote the final consumption expenditure by households and by non-profit organizations, respectively.

Accordingly, we define private final consumption as

$$
\text { Fcons }_{C j}^{U}=C O N S_{-} h_{C j}^{U}+C O N S_{-} n p_{C j}^{U},
$$

and thus

$$
\Delta \text { cons }_{C j}^{U}=\Delta F_{C j}^{U} \cdot \frac{C O N S_{-} h_{C j}^{U}+C O N S_{-} n p_{C j}^{U}}{F_{C j}^{U}} .
$$

Finally, the incremental U.S. tariff revenue from the tariff increase is

$$
\operatorname{TRev}_{C j}^{U}=T C R_{C j}^{U} \cdot \Delta \tau \cdot\left(1+\frac{\Delta F_{C j}^{U}+\Delta Z_{C j}^{U}}{F_{C j}^{U}+Z_{C j}^{U}}\right)^{\frac{\sigma_{C j}^{U}}{1+\sigma_{C j}^{U}}} \cdot \frac{F_{C j}^{U}+Z_{C j}^{U}}{1+\tau} \text { for } j=1 \ldots 20
$$

As discussed above, total losses (TLoss ${ }_{C j}^{U}$ ) are measured by $D W L_{C j}^{U}+\lambda \cdot \operatorname{TRe} v_{C j}^{U}$, depending crucially on the leakage rate $\lambda$. In the absence of a precise measure of $\lambda$, we measure it as 1 minus the fiscal multiplier. Owyang, Ramey, and Zubairy (2013) estimate that the U.S. fiscal multipliers range from 0.7 to 0.9 . We take their findings and assume $1-\lambda=0.8$. We then report the total losses for each sector as the sum of our benchmark measure of deadweight losses and $\lambda$ times the incremental tariff revenue. We summarize these results in Tables 4 to 7 (measured in US\$ millions). 


\section{Table 4}

\section{Sectoral Impacts on Chinese Output}

\begin{tabular}{|c|c|c|}
\hline WIOD sector & $\Delta X_{C j}$ (US\$ millions) & $\Delta F_{C j}^{U}+\Delta Z_{C j}^{U}$ (US\$ millions) \\
\hline A01-03: Primary & $-3,216$ & -303 \\
\hline C10-12: Food and Tobacco & $-2,980$ & -599 \\
\hline C13-15: Textile & $-7,181$ & $-3,175$ \\
\hline C16: Wood & $-2,335$ & -774 \\
\hline C17: Paper & $-1,534$ & $-1,385$ \\
\hline C18: Printing and Media & -348 & -93 \\
\hline C19: Petroleum & $-3,084$ & $-1,207$ \\
\hline C20: Chemicals & $-5,979$ & $-1,290$ \\
\hline C21: Pharmaceutical & -650 & -243 \\
\hline C22: Plastic and Rubber & $-2,855$ & -278 \\
\hline C23: Non-metallic Mineral & $-2,429$ & -174 \\
\hline C24: Basic Metals & $-8,939$ & -973 \\
\hline C25: Metal Products & $-4,525$ & $-3,892$ \\
\hline C26: Electronic and ICT & $-32,849$ & $-23,103$ \\
\hline C27: Electrical Equipment & $-11,730$ & $-9,520$ \\
\hline C28: Machinery & $-2,773$ & -478 \\
\hline C29: Motor Vehicles & $-1,377$ & -688 \\
\hline C30: Other Transport & -98 & 139 \\
\hline C31-32: Furniture & $-3,692$ & $-3,504$ \\
\hline C33: Repair and Installation & 0 & 0 \\
\hline Total & $-98,574$ & $-51,540$ \\
\hline
\end{tabular}

NOTE: $\Delta X_{C j}$, derived according to (21), measures the impacts on the sectoral output in China through the international inputoutput linkage when the United States raises import tariffs against China. $\Delta F_{C j}^{U}+\Delta Z_{C j}^{U}$, derived according to (22) and (24), is the estimated change in U.S. import demand for Chinese goods due to the U.S. tariff war against China.

Two measures of the sectoral impacts on Chinese output are reported in Table 4 . We classify sectoral impacts into four groups by the magnitude of the impact. The groups for the first measure (the changes in the sum of U.S. final demand and intermediate demand for Chinese goods) are as follows:

(i) The high-impact group (U.S. demand lowered by more than $\$ 5$ billion) includes the Electronic and ICT industry and the Electrical industry, whose U.S. demands are lowered by $\$ 23$ and $\$ 9.5$ billion, respectively.

(ii) The sizable-impact group (U.S. demand lowered by more than $\$ 1$ billion but less than $\$ 5$ billion) includes the Metal Products; Furniture; Textiles; Paper; Chemicals; and Petroleum industries, ordered by size from high to low.

(iii) The moderate-impact group (U.S. demand lowered by more than $\$ 500$ million but less than $\$ 1$ billion) includes the Basic Metals; Wood; Motor Vehicles; and Food industries, ordered by size from high to low. 


\section{Table 5}

\section{Sectoral Impacts on U.S. Output}

\begin{tabular}{|c|c|c|}
\hline WIOD sector & $\Delta X_{U j}$ (US\$ millions) & $\Delta X_{U j} / X_{U j}(\% \circ)$ \\
\hline A01-03: Primary & -46.41 & -0.095 \\
\hline C10-12: Food and Tobacco & -22.45 & -0.023 \\
\hline C13-15: Textile & -4.89 & -0.052 \\
\hline C16: Wood & -9.44 & -0.096 \\
\hline C17: Paper & -22.60 & -0.117 \\
\hline C18: Printing and Media & -2.70 & -0.032 \\
\hline C19: Petroleum & -37.69 & -0.046 \\
\hline C20: Chemicals & -97.24 & -0.163 \\
\hline C21: Pharmaceutical & -15.34 & -0.072 \\
\hline C22: Plastic and Rubber & -17.95 & -0.078 \\
\hline C23: Non-metallic Mineral & -7.28 & -0.063 \\
\hline C24: Basic Metals & -36.28 & -0.129 \\
\hline C25: Metal Products & -27.19 & -0.072 \\
\hline C26: Electronic and ICT & -137.27 & -0.355 \\
\hline C27: Electrical Equipment & -22.08 & -0.176 \\
\hline C28: Machinery & -31.31 & -0.077 \\
\hline C29: Motor Vehicles & -10.82 & -0.018 \\
\hline C30: Other Transport & -12.33 & -0.036 \\
\hline C31-32: Furniture & -10.61 & -0.044 \\
\hline C33: Repair and Installation & -0.25 & -0.007 \\
\hline Total & -572.13 & -0.085 \\
\hline
\end{tabular}

NOTE: $\Delta X_{U j}$, derived according to (21), measures the impacts on the sectoral output in the United States through the international input-output linkage when the United States raises import tariffs against China. $X_{U j}$ is directly obtained from WIOT and corresponds to sectoral gross output in the base year.

(iv) The low-impact group (U.S. demand lowered by less than $\$ 500$ million) includes all other industries: Machinery; Primary; Plastic and Rubber; Pharmaceutical; Mineral; Printing and Media; Other Transport; and Repair and Installation.

The groups for the second measure (the changes in sectoral output in China resulting from the changes in U.S. demand for Chinese goods, through international input-output linkages) are as follows:

(i) The high-impact group (Chinese sectoral output lowered by more than $\$ 5$ billion) includes the Electronic and ICT; Electrical; Basic Metals; Textiles; and Chemicals industries, whose Chinese output is lowered by $\$ 33$ billion, $\$ 12$ billion, $\$ 9$ billion, $\$ 7$ billion, and $\$ 6$ billion, respectively.

(ii) The sizable-impact group (Chinese sectoral output lowered by more than $\$ 3$ billion but less than $\$ 5$ billion) includes the Metal Products; Furniture; Primary; and Petroleum industries, ordered by size from high to low. 


\section{Table 6}

\section{U.S. Deadweight Losses}

\begin{tabular}{|c|c|c|c|}
\hline WIOD sector & $\begin{array}{c}\text { Measure } 1 \\
\text { (US\$ millions) }\end{array}$ & $\begin{array}{c}\text { Measure } 2 \\
\text { (US\$ millions) }\end{array}$ & $\begin{array}{c}\text { Measure } 3 \\
\text { (US\$ millions) }\end{array}$ \\
\hline A01-03: Primary & 11.62 & 5.12 & 5.12 \\
\hline C10-12: Food and Tobacco & 39.51 & 35.17 & 34.80 \\
\hline C13-15: Textile & 16.00 & 15.43 & 15.41 \\
\hline C16: Wood & 26.02 & 13.08 & 11.05 \\
\hline C17: Paper & 45.30 & 15.20 & 14.60 \\
\hline C18: Printing and Media & 3.04 & 2.45 & 2.09 \\
\hline C19: Petroleum & 46.12 & 20.62 & 19.81 \\
\hline C20: Chemicals & 46.56 & 8.76 & 7.74 \\
\hline C21: Pharmaceutical & 8.77 & 5.75 & 5.55 \\
\hline C22: Plastic and Rubber & 21.37 & 12.43 & 12.24 \\
\hline C23: Non-metallic Mineral & 6.26 & 3.23 & 2.97 \\
\hline C24: Basic Metals & 52.14 & 23.77 & 19.30 \\
\hline C25: Metal Products & 169.38 & 93.42 & 54.27 \\
\hline C26: Electronic and ICT & 522.47 & 428.28 & 92.18 \\
\hline C27: Electrical Equipment & 206.16 & 159.65 & 73.83 \\
\hline C28: Machinery & 35.12 & 24.22 & 2.08 \\
\hline C29: Motor Vehicles & 60.08 & 23.93 & 11.15 \\
\hline C30: Other Transport & 3.56 & 2.65 & 1.83 \\
\hline C31-32: Furniture & 135.94 & 131.61 & 119.28 \\
\hline C33: Repair and Installation & 0.00 & 0.00 & 0.00 \\
\hline Total & $1,455.42$ & $1,024.77$ & 505.29 \\
\hline
\end{tabular}

NOTE: Measure 1 of the DWL is our benchmark, which considers both final demand and intermediate demand. Measure 2 of the $D W L$ considers only final demand. Measure 3 of the $D W L$ considers only private final consumption demand.

(iii) The moderate-impact group (Chinese sectoral output lowered by more than $\$ 1$ billion but less than $\$ 3$ billion) includes the Food; Plastic and Rubber; Machinery; Mineral; Wood; Paper; and Motor Vehicles industries, ordered by size from high to low.

(iv) The low-impact group (Chinese sectoral output lowered by less than $\$ 1$ billion) includes all other industries: Pharmaceuticals; Printing and Media; Other Transport; and Repair and Installation.

Notably, the aggregate impact on Chinese output is $-\$ 98.5$ billion, while the measured changes in U.S. demand for Chinese goods are $-\$ 39$ billion for final demand and $-\$ 13$ billion for intermediate demand. These findings suggest that, as U.S. import demand for Chinese goods is depressed by higher tariffs, the resulting impact on Chinese output is amplified when the international input-output linkage is considered.

Similarly, we can classify the U.S. sectoral deadweight losses, as reported in Table 6, into the four groups by size: 


\section{Table 7}

\section{U.S. Deadweight Losses, Tariff Revenue, and Total Losses}

\begin{tabular}{|c|c|c|c|c|}
\hline WIOD sector & $\begin{array}{l}D W L_{C j}^{U}(F \& Z) \\
\text { (US\$ millions) }\end{array}$ & $\begin{array}{c}\operatorname{TRev}_{C j}^{U} \\
\text { (US\$ millions) }\end{array}$ & $\begin{array}{c}T L o s s_{C j}^{U} \\
\text { (US\$ millions) }\end{array}$ & $\begin{array}{c}\text { FLoss } U_{C j}^{U} \\
\text { (US\$ millions) }\end{array}$ \\
\hline A01-03: Primary & 11.62 & 27.09 & 17.04 & 38.71 \\
\hline C10-12: Food and Tobacco & 39.51 & 331.15 & 105.74 & 370.67 \\
\hline C13-15: Textile & 16.00 & 431.60 & 102.32 & 447.60 \\
\hline C16: Wood & 26.02 & 51.02 & 36.22 & 77.04 \\
\hline C17: Paper & 45.30 & 51.88 & 55.68 & 97.18 \\
\hline C18: Printing and Media & 3.04 & 3.48 & 3.74 & 6.52 \\
\hline C19: Petroleum & 46.12 & 0.79 & 46.28 & 46.91 \\
\hline C20: Chemicals & 46.56 & 561.64 & 158.89 & 608.21 \\
\hline C21: Pharmaceutical & 8.77 & 105.74 & 29.92 & 114.51 \\
\hline C22: Plastic and Rubber & 21.37 & 394.79 & 100.33 & 416.17 \\
\hline C23: Non-metallic Mineral & 6.26 & 117.05 & 29.67 & 123.30 \\
\hline C24: Basic Metals & 52.14 & 378.19 & 127.78 & 430.33 \\
\hline C25: Metal Products & 169.38 & 497.33 & 268.85 & 666.72 \\
\hline C26: Electronic and ICT & 522.47 & $2,575.14$ & $1,037.50$ & $3,097.61$ \\
\hline C27: Electrical Equipment & 206.16 & 612.25 & 328.61 & 818.42 \\
\hline C28: Machinery & 35.12 & $1,033.87$ & 241.89 & $1,068.99$ \\
\hline C29: Motor Vehicles & 60.08 & 761.87 & 212.45 & 821.94 \\
\hline C30: Other Transport & 3.56 & 225.38 & 48.64 & 228.94 \\
\hline C31-32: Furniture & 135.94 & $1,044.79$ & 344.90 & $1,180.73$ \\
\hline C33: Repair and Installation & 0.00 & 0.00 & 0.00 & 0.00 \\
\hline Total & $1,455.42$ & $9,205.06$ & $3,296.43$ & $10,660.48$ \\
\hline
\end{tabular}

NOTE: The deadweight losses are measured in dollar terms (numbers are reported in million US\$). $D W L_{C j}^{U}$ reports our benchmark measures of the deadweight loss. TRev $C_{C,}^{U}$, derived from (3), estimates the incremental tariff revenue due to the U.S. import tariff rise. Total losses TLoss ${ }_{C j}^{U}$ are the sum of the benchmark measure of deadweight losses and $\lambda$ times the incremental tariff revenue. The full leakage losses $F L o s s_{C j}^{U}$ are the sum of $D W L_{C j}^{U}$ and $T R e{ }_{C j}^{U}$.

(i) The high-impact group (sectoral deadweight losses of more than $\$ 100$ million) includes the Electronic and ICT; Electrical; Metal Products; and Furniture industries, whose benchmark deadweight losses are \$522 million, \$206 million, \$169 million, and \$136 million, respectively.

(ii) The sizable-impact group (sectoral deadweight losses of more than $\$ 40$ million but less than $\$ 100$ million) includes the Motor Vehicles; Basic Metals; Chemicals; Petroleum; and Paper industries, ordered by the size from high to low.

(iii) The moderate-impact group (sectoral deadweight losses of more than $\$ 20$ million but less than $\$ 40$ million) includes the Food; Machinery; Wood; and Plastic and Rubber industries, ordered by the size from high to low. 
(iv) The low-impact group (sectoral deadweight losses of less than $\$ 20$ million) includes all other industries: Textiles; Primary; Pharmaceutical; Mineral; Other Transport; Printing and Media; and Repair and Installation.

It is worth noting that, as reported in Table 5, the trade war impacts the output of the U.S. Electronic and ICT industry and Chemicals industry the most, \$137 million and \$97 million, respectively. These industries also bear the highest measured deadweight losses (Electronic and ICT in the high-impact group and Chemicals in the sizable-impact group). Likewise, most industries also sort into comparable groups in the sectoral output impact measure and the deadweight losses measure. However, it is interesting to note that although the Electrical; Metal Products; and Furniture industries only face moderate-to-low sectoral output impacts (\$27 million, \$22 million, and \$11 million, respectively), they fall into the high-impact group for deadweight losses-because of differences in their demand responses and supply responses under heterogeneous tariffs and differences in their positions in the global value chain upstream and downstream. The Electrical industry has high trade elasticity (highly responsive demand), whereas the Metal Products industry faces high tariff coverage (high TCR); both are highly China dependent, particularly for their downstream products (high FDR). Similarly, the impact on the output of the Motor Vehicles industry is low (\$11 million), but that industry encounters sizable deadweight losses. Conversely, the impact on the output of the Primary industry is sizable ( $\$ 46$ million), but the industry is classified in the lowimpact group for deadweight losses.

Aggregate deadweight losses are $\$ 1.5$ billion in our benchmark measure, which considers both intermediate demand and final demand. When only considering final demand or private final consumption demand, the aggregate deadweight losses are $\$ 1$ billion and $\$ 0.5$ billion, respectively. Finally, as reported in Table 7, the measured total losses, which sum the benchmark deadweight losses and the estimated incremental tariff revenue that is not redistributed back to consumers or importers, are an aggregate $\$ 3.3$ billion, around 0.05 percent of gross U.S. output. Our results can also be compared with the estimates in Amiti, Redding, and Weinstein (2019), where for 2018 the yearly cumulative deadweight losses are estimated (at 2018 prices) to be $\$ 8.2$ billion and the tariff revenue is estimated to be $\$ 15.6$ billion, for total losses of $\$ 23.8$ billion.

The main takeaways of the quantitative analysis are summarized as follows. First, because of imbalanced trade, a trade war's sectoral impacts on Chinese sectors are generally larger than those on U.S. sectors, with Chinese output dropping by $\$ 98.5$ billion and U.S. demand for Chinese goods dropping by $\$ 39$ billion for final demand and by $\$ 13$ billion for intermediate demand. Second, the Electronic and ICT industry and the Electrical industry encounter the largest drops in demand for Chinese goods, with their total demands dropping by $\$ 23$ billion and $\$ 9.5$ billion, respectively. Third, based on our benchmark measure, the aggregate U.S. deadweight losses are $\$ 1.5$ billion. Among all sectors, the Electronic and ICT; Electrical; Metal Products; and Furniture industries suffer the greatest losses, \$522 million, \$206 million, \$169 million, and \$136 million, respectively. Fourth, with a leakage rate of 20 percent, total losses to U.S. consumers and importers are $\$ 3.3$ billion, about 0.05 percent of gross output and two-thirds as much as the annual welfare gains from NAFTA. The full leakage losses are $\$ 10.7$ billion, or 0.16 percent of gross output, which is twice as much as the annual welfare gains from NAFTA. 


\section{CONCLUSIONS}

In this article, we have established an accounting framework that assesses the sectoral impacts of the U.S.-China trade war with regards to output, demand, deadweight losses, total losses, and full leakage losses. We have found nonnegligible detrimental effects for the United States, with total losses and full leakage losses about two-thirds and twice as much as the annual welfare gains from NAFTA, respectively. While the takeaway message is clear-initiating a trade war is costly to the domestic economy - it would also be valuable to evaluate the detrimental consequences of such a global conflict by using a broader scope. It would be particularly rewarding to build a deep structural model to quantify how the global value chain is reshuffled during a trade war, which may shed light on the longer-run impacts on international demands, pricing strategies, and hence welfare.

\section{APPENDIX}

\section{Table A1}

World Input-Output Table for Two Industries and Three Countries, in Monetary Units

\begin{tabular}{|c|c|c|c|c|c|c|c|c|c|c|c|}
\hline & & \multicolumn{2}{|c|}{ Country 1} & \multicolumn{2}{|c|}{ Country 2} & \multicolumn{2}{|c|}{ Country 3} & \multirow[b]{2}{*}{$F D^{1}$} & \multirow[b]{2}{*}{$F D^{2}$} & \multirow[b]{2}{*}{$F D^{3}$} & \multirow[b]{2}{*}{ Total } \\
\hline & & Ind 1 & Ind 2 & Ind 1 & Ind 2 & Ind 1 & Ind 2 & & & & \\
\hline \multirow{2}{*}{ Country 1} & Ind 1 & 2 & 3 & 1 & 2 & 0 & 1 & 2 & 1 & 0 & 12 \\
\hline & Ind 2 & 0 & 1 & 0 & 1 & 2 & 0 & 2 & 0 & 0 & 6 \\
\hline \multirow{2}{*}{ Country 2} & Ind 1 & 1 & 1 & 2 & 0 & 1 & 1 & 0 & 2 & 0 & 8 \\
\hline & Ind 2 & 3 & 0 & 0 & 2 & 0 & 0 & 0 & 3 & 0 & 8 \\
\hline \multirow{4}{*}{ Country 3} & Ind 1 & 1 & 0 & 1 & 0 & 3 & 0 & 0 & 0 & 3 & 8 \\
\hline & Ind 2 & 0 & 0 & 0 & 1 & 1 & 2 & 0 & 1 & 1 & 6 \\
\hline & VA & 5 & 1 & 4 & 2 & 1 & 2 & & & & \\
\hline & GO & 12 & 6 & 8 & 8 & 8 & 6 & & & & \\
\hline
\end{tabular}

NOTE: Ind, industry; $F D$, final demand, where $F D^{j}$ denotes the final demand by country $j$; VA, value added; and GO, gross output.

Table A1 is a simple example of the data in the WIOT. Transforming the WIOT into the expression of the Leontief framework, we have

$$
X=Z i+F=A X+F,
$$

where $X$ is gross output, $Z$ intermediate demand, $i$ a column vector of 1 , and $A$ the input technology matrix. The gross output matrix is 


$$
X=\left[\begin{array}{c}
X_{c 1(d 1)} \\
X_{c 1(d 2)} \\
X_{c 2(d 1)} \\
X_{c 2(d 2)} \\
X_{c 3(d 1)} \\
X_{c 3(d 2)}
\end{array}\right]=\left[\begin{array}{c}
12 \\
6 \\
8 \\
8 \\
8 \\
6
\end{array}\right],
$$

the intermediate demand is

$$
Z=\left[\begin{array}{llllll}
z_{c 1(d 1) c 1(d 1)} & z_{c 1(d 1) c 1(d 2)} & z_{c 1(d 1) c 2(d 1)} & z_{c 1(d 1) c 2(d 2)} & z_{c 1(d 1) c 3(d 1)} & z_{c 1(d 1) c 3(d 2)} \\
z_{c 1(d 2) c 1(d 1)} & z_{c 1(d 2) c 1(d 2)} & z_{c 1(d 2) c 2(d 1)} & z_{c 1(d 2) c 2(d 2)} & z_{c 1(d 2) c 3(d 1)} & z_{c 1(d 2) c 3(d 2)} \\
z_{c 2(d 1) c 1(d 1)} & z_{c 2(d 1) c 1(d 2)} & z_{c 2(d 1) c 2(d 1)} & z_{c 2(d 1) c 2(d 2)} & z_{c 2(d 1) c 3(d 1)} & z_{c 2(d 1) c 3(d 2)} \\
z_{c 2(d 2) c 1(d 1)} & z_{c 2(d 2) c 1(d 2)} & z_{c 2(d 2) c 2(d 1)} & z_{c 2(d 2) c 2(d 2)} & z_{c 2(d 2) c 3(d 1)} & z_{c 2(d 2) c 3(d 2)} \\
z_{c 3(d 1) c 1(d 1)} & z_{c 3(d 1) c 1(d 2)} & z_{c 3(d 1) c 2(d 1)} & z_{c 3(d 1) c 2(d 2)} & z_{c 3(d 1) c 3(d 1)} & z_{c 3(d 1) c 3(d 2)} \\
z_{c 3(d 2) c 1(d 1)} & z_{c 3(d 2) c 1(d 2)} & z_{c 3(d 2) c 2(d 1)} & z_{c 3(d 2) c 2(d 2)} & z_{c 3(d 2) c 3(d 1)} & z_{c 3(d 2) c 3(d 2)}
\end{array}\right]=\left[\begin{array}{cccccc}
2 & 3 & 1 & 2 & 0 & 1 \\
0 & 1 & 0 & 1 & 2 & 0 \\
1 & 1 & 2 & 0 & 1 & 1 \\
3 & 0 & 0 & 2 & 0 & 0 \\
1 & 0 & 1 & 0 & 3 & 0 \\
0 & 0 & 0 & 1 & 1 & 2
\end{array}\right],
$$

and the final demand is

$$
F=\left[\begin{array}{c}
F_{c 1 d 1}^{c 1}+F_{c 1 d 1}^{c 2}+F_{c 1 d 1}^{c 3} \\
F_{c 1 d 2}^{c 1}+F_{c 1 d 2}^{c 2}+F_{c 1 d 2}^{c 3} \\
F_{c 2 d 1}^{c 1}+F_{c 2 d 1}^{c 2}+F_{c 2 d 1}^{c 3} \\
F_{c 2 d 2}^{c 1}+F_{c 2 d 2}^{c 2}+F_{c 2 d 2}^{c 3} \\
F_{c 3 d 1}^{c 1}+F_{c 3 d 1}^{c 2}+F_{c 3 d 1}^{c 3} \\
F_{c 3 d 2}^{c 1}+F_{c 3 d 2}^{c 2}+F_{c 3 d 2}^{c 3}
\end{array}\right]=\left[\begin{array}{c}
2+1+0 \\
2+0+0 \\
0+2+0 \\
0+3+0 \\
0+0+3 \\
0+1+1
\end{array}\right]=\left[\begin{array}{l}
3 \\
2 \\
2 \\
3 \\
3 \\
2
\end{array}\right]
$$

The Leontief input technology matrix specified as $A=\left[a_{k(i) s(j)}\right]=\left[\frac{z_{k(i) s(j)}}{X_{s(j)}}\right]$ is thus

$$
A=\left[\begin{array}{llllll}
A_{c 1(d 1) c 1(d 1)} & A_{c 1(d 1) c 1(d 2)} & A_{c 1(d 1) c 2(d 1)} & A_{c 1(d 1) c 2(d 2)} & A_{c 1(d 1) c 3(d 1)} & A_{c 1(d 1) c 3(d 2)} \\
A_{c 1(d 2) c 1(d 1)} & A_{c 1(d 2) c 1(d 2)} & A_{c 1(d 2) c 2(d 1)} & A_{c 1(d 2) c 2(d 2)} & A_{c 1(d 2) c 3(d 1)} & A_{c 1(d 2) c 3(d 2)} \\
A_{c 2(d 1) c 1(d 1)} & A_{c 2(d 1) c 1(d 2)} & A_{c 2(d 1) c 2(d 1)} & A_{c 2(d 1) c 2(d 2)} & A_{c 2(d 1) c 3(d 1)} & A_{c 2(d 1) c 3(d 2)} \\
A_{c 2(d 2) c 1(d 1)} & A_{c 2(d 2) c 1(d 2)} & A_{c 2(d 2) c 2(d 1)} & A_{c 2(d 2) c 2(d 2)} & A_{c 2(d 2) c 3(d 1)} & A_{c 2(d 2) c 3(d 2)} \\
A_{c 3(d 1) c 1(d 1)} & A_{c 3(d 1) c 1(d 2)} & A_{c 3(d 1) c 2(d 1)} & A_{c 3(d 1) c 2(d 2)} & A_{c 3(d 1) c 3(d 1)} & A_{c 3(d 1) c 3(d 2)} \\
A_{c 3(d 2) c 1(d 1)} & A_{c 3(d 2) c 1(d 2)} & A_{c 3(d 2) c 2(d 1)} & A_{c 3(d 2) c 2(d 2)} & A_{c 3(d 2) c 3(d 1)} & A_{c 3(d 2) c 3(d 2)}
\end{array}\right]=\left[\begin{array}{cccccc}
\frac{2}{12} & \frac{3}{6} & \frac{1}{8} & \frac{2}{8} & 0 & \frac{1}{6} \\
0 & \frac{1}{6} & 0 & \frac{1}{8} & \frac{2}{8} & 0 \\
\frac{1}{12} & \frac{1}{6} & \frac{2}{8} & 0 & \frac{1}{8} & \frac{1}{6} \\
\frac{3}{12} & 0 & 0 & \frac{2}{8} & 0 & 0 \\
\frac{1}{12} & 0 & \frac{1}{8} & 0 & \frac{3}{8} & 0 \\
0 & 0 & 0 & \frac{1}{8} & \frac{1}{8} & \frac{2}{6}
\end{array}\right] .
$$




\section{NOTES}

1 This assumption is possibly in effect with a quality ladder model, where sector-j goods produced by different countries are of different quality, consumers and firms treat goods of different quality as different varieties, and both the preference and investment technology are Leontief.

2 It is possible that complete pass-through may not be hold up universally in other circumstances.

3 The tariff coverage rate, taken from Bown (2019), is defined as the share of U.S. imports from China affected by U.S. special protection.

4 Caliendo and Parro (2015) estimate trade elasticities using NAFTA data. We use their estimates for the value of $\sigma_{C j}^{U}$. It should be noted that it implies the implicit assumption that $\sigma_{s j}^{d}=\sigma_{s^{\prime} j}^{d}$ for all $s \neq s^{\prime}$.

5 We provide a simple example in the appendix to illustrate the data structure of the WIOT and how to transform the data to the Leontief framework.

\section{REFERENCES}

Alvarez, Fernando and Lucas, Robert E. "General Equilibrium Analysis of the Eaton-Kortum Model of International Trade." Journal of Monetary Economics, 2007, 54(6), pp. 1726-68; https://doi.org/10.1016/j.jmoneco.2006.07.006.

Amiti, Mary; Kong, Sang Hoon and Weinstein, David E. "The Effect of the U.S.-China Trade War on U.S. Investment." NBER Working Paper 27114, National Bureau of Economic Research, 2020; https://doi.org/10.3386/w27114.

Amiti, Mary; Redding, Stephen J. and Weinstein, David E. "The Impact of the 2018 Tariffs on Prices and Welfare." Journal of Economic Perspectives, 2019, 33(4), pp. 187-210; https://doi.org/10.1257/jep.33.4.187.

Arkolakis, Costas; Costinot, Arnaud and Rodríguez-Clare, Andrés. "New Trade Models, Same Old Gains?" American Economic Review, 2012, 102(1), pp. 94-130; https://doi.org/10.1257/aer.102.1.94.

Bloom, Nicholas; Romer, Paul M.; Terry, Stephen J. and Van Reenen, John. "A Trapped-Factors Model of Innovation." American Economic Review, 2013, 103(3), pp. 208-13; http://dx.doi.Org/10.1257/aer.103.3.208.

Bown, Chad P. “The 2018 US-China Trade Conflict After Forty Years of Special Protection.” CEPR Discussion Paper No. 13695, Centre for Economic Policy Research, 2019; https://cepr.org/active/publications/discussion_papers/dp.php?dpno=13695.

Bown, Chad P. and Crowley, Meredith A. "The Empirical Landscape of Trade Policy," in Kyle Bagwell and Robert W. Staiger, eds., Handbook of Commercial Policy. Volume 1A. Elsevier, North Holland, 2016, pp. 3-108; https://www.sciencedirect.com/science/article/pii/S2214312216300151.

Caliendo, Lorenzo and Parro, Fernando. "Estimates of the Trade and Welfare Effects of NAFTA." Review of Economic Studies, 2015, 82(1), pp. 1-44; https://doi.org/10.1093/restud/rdu035.

Cavallo, Alberto; Gopinath, Gita; Neiman, Brent and Tang, Jenny. "Tariff Pass-Through at the Border and at the Store: Evidence from US Trade Policy." American Economic Review: Insights, 2021, 3(1), pp. 19-34; https://doi.org/10.1257/aeri.20190536.

Chen, Ching-Mu; Cheng, Wan-Jung; Peng, Shin-Kun; Riezman, Raymond G. and Wang, Ping. "Trade Wars and Technology Choice." NBER Working Paper 26468, National Bureau of Economic Research, 2020; https://doi.org/10.3386/w26468.

Diamond, Peter A. and Mirrlees, James A. "Optimal Taxation and Public Production I: Production Efficiency." American Economic Review, 1971, 61(1), pp. 8-27; https://www.jstor.org/stable/1910538.

Fajgelbaum, Pablo D.; Goldberg, Pinelopi K.; Kennedy, Patrick J. and Khandelwal Amit K. "The Return to Protectionism." Quarterly Journal of Economics, 2020, 135(1), pp. 1-55; https://doi.org/10.1093/qje/qjz036.

Hsieh, Chang-Tai; Klenow, Peter J. and Nath, Ishan B. "A Global View of Creative Destruction." NBER Working Paper No. w26461, 2019; https://doi.org/10.3386/w26461.

Kennan, John and Riezman, Raymond G. "Do Big Countries Win Tariff Wars?" International Economic Review, 1988, 29(1), pp. 81-85; https://doi.org/10.2307/2526808.

Kindleberger, Charles P. "Commercial Policy Between the Wars," in Peter Mathias, and Sidney Pollard, eds., The Cambridge Economic History of Europe from the Decline of the Roman Empire. Chapter 2. Cambridge: Cambridge University Press, 1989; https://doi.org/10.1017/CHOL9780521225045.003. 
Ossa, Ralph. "Trade Wars and Trade Talks with Data." American Economic Review, 2014, 104(12), pp. 4104-46; https://doi.org/10.1257/aer.104.12.4104.

Owyang, Michael T.; Ramey, Valerie A. and Zubairy, Sarah. "Are Government Spending Multipliers Greater during Periods of Slack? Evidence from Twentieth-Century Historical Data." American Economic Review, 2013, 103(3), pp. 129-134; https://doi.org/10.1257/aer.103.3.129.

Perla, Jesse; Tonetti, Christopher and Waugh, Michael E. "Equilibrium Technology Diffusion, Trade, and Growth." American Economic Review, January 2021, 111(1), pp. 73-128; https://doi.org/10.1257/aer.20151645.

Santacreu, Ana Maria and Peake, Makenzie. "The Economic Effects of the 2018 U.S. Trade Policy: A State-Level Analysis." Federal Reserve Bank of St. Louis Review, Fourth Quarter 2020, 102(4), pp. 385-412; https://doi.org/10.20955/r.102.385-412.

Timmer, Marcel P.; Dietzenbacher, Eric; Los, Bart; Stehrer, Robert and de Vries, Gaaitzen J. "An Illustrated User Guide to the World Input-Output Database: the Case of Global Automotive Production." Review of International Economics, 2015, 23(3), pp. 575-605; https://doi.org/10.1111/roie.12178. 